\section{RESPONSE}

\section{Sharing is caring, but more clarity is needed}

\author{
Holly McEntee, Derrik Duchesneau, \\ Melissa Hunsley \& \\ Sarah Johnson-Schlueter
}

This scenario demonstrates the challenges of creating a post-approval monitoring (PAM) program that best fits each institution's animal program structure and research culture in the absence of clear and detailed regulatory requirements for $\mathrm{PAM}^{1}$. In preparing this response, my PAM colleagues were convinced that the IACUC Chair is indeed the supervisor of the PAM specialists, whereas from my perspective as IACUC Administrator I am equally convinced the Chair is not.

Strictly speaking, the PAM specialists' "reporting" to the IACUC is simply that: delivering information to the IACUC for its use in decision-making and determining next steps. It is frustrating when an IACUC fails to act as a supporting staff member believes is appropriate. However if Ms. Hall truly believes that the institution is at risk due to the inaction of the IACUC there are two other authorities she could approach: the Institutional Official (IO), and the Attending Veterinarian (AV).

Ms. Hall should do some investigating to find out if the incident really does need to be reported to NIH/OLAW by asking the following question: Is PHS or NSF funding used to conduct work on the protocol in question? If yes, Hall should meet with Dr. Covelli to express her concerns and explain that following federal policy ${ }^{2}$ is in the best interest of the university. If Dr. Covelli still refuses to report the incident to NIH/OLAW, Hall should notify him that she will raise the issue for full discussion at the next IACUC meeting. Hall could also approach the AV and express her concern, because animals were put at increased risk of post-operative pain and distress due to the protocol violation. At the IACUC meeting when Hall raises the issue the combined opinions of both the AV and Hall will provide the full IACUC with a more complete set of information that

\title{
A Word from OLAW
}

In response to the questions posed in this scenario, the Office of Laboratory Animal Welfare (OLAW) provides the following clarifications.

The PHS Policy does not specifically address reporting channels for post-approval monitoring (PAM) personnel. OLAW recommends in previous guidance that direct, clear and straightforward lines of responsibility and corresponding authority allow organizations to respond quickly and effectively ${ }^{1}$. The Institutional Official (I0) in the scenario should clearly define and assign responsibilities and reporting channels for monitoring animal care and use to safeguard animal welfare ${ }^{2}$. While not required by the PHS Policy, a PAM program helps ensure the wellbeing of the animals and may also provide opportunities to refine research procedures ${ }^{3}$. If the study in question was PHS or NSF-supported, the incident qualifies as reportable to OLAW because it was a "failure to adhere to an IACUC-approved protocol"4. As such, the IACUC must be informed of the incident and through the IO promptly provide OLAW with an explanation of the circumstances and the actions taken to address the noncompliance.

1. Public Health Service. Policy on Humane Care and Use of Laboratory Animals - Frequently Asked Questions. Institutional Responsibilities, Question No. G.4. (US Department of Health and Human Services, Washington, DC, 2006, revised 2017). https://grants.nih.gov/grants/olaw/faqs.htm\#680

2. Institute for Laboratory Animal Research. Guide for the Care and Use of Laboratory Animals 8th edn. pp. 23-24 (National Academies Press, Washington, DC, 2011).

3. Public Health Service. Policy on Humane Care and Use of Laboratory Animals - Frequently Asked Questions. Institutional Responsibilities, Question No. G.6. (US Department of Health and Human Services, Washington, DC, 2006, revised 2017). https://grants.nih.gov/grants/olaw/faqs.htm\#682

4. National Institutes of Health. Notice NOT-0D-05-034, Guidance on Prompt Reporting to OLAW [online]. http://grants.nih.gov/grants/guide/notice-files/NOT-0D-05-034.html (National Institutes of Health, Washington, DC, 24 February 2005).

Patricia Brown, VMD, MS, DACLAM

Director

OLAW, OER, OD, NIH, HHS

the IACUC can then act upon. If the IACUC still will not report the issue, Hall (and perhaps the AV) should express her concerns to the IO. At this point she has done her due diligence and it is up to the IO and IACUC to decide how to handle issues such as this. If Hall is a member of the IACUC, she could author a minority opinion regarding the decision if she is comfortable with her opinion being included in the semiannual program review report to the IO and OLAW (if the institution holds an Assurance) ${ }^{3}$.

Ms. Hall's fear of reprisal if she approached the IO as her co-worker advised is a concern. This suggests a work environment that is not conducive to fulfilling the Guide and regulatory expectations for postapproval monitoring ${ }^{4,5}$, and may violate rules (ref. 6; $\$ 2.32, c, 4$ ) on reprisals against employees who express concerns about research animals.

We recommend that the PAM specialists ask for clarification regarding workplace reporting lines and supervisory authority, and to continue providing the IACUC with thoughtful, accurate reports about the animal program they oversee.

1. Banks, Ron E. 2014. Postapproval monitoring. In: The IACUC Handbook 3rd edn. (ed. Silverman, J., Suckow, M. \& Murthy, S.) (CRC Press, Boca Raton, 2014).

2. Public Health Service. Policy on Humane Care and Use of Laboratory Animals. (US Department of Health and Human Services, Washington, DC, 1986; revised 2015).

3. National Institutes of Health, Office of Laboratory Animal Welfare. FAQ C.6, What are PHS requirements for recording and reporting minority views? https://grants.nih.gov/grants/ olaw/faqs.htm\#612

4. Institute for Laboratory Animal Research. Guide for the Care and Use of Laboratory Animals 8th edn. (National Academies Press, Washington, DC, 2011).

5. United States Department of Agriculture. Animal Welfare Inspection Guide (US Department of Agriculture, Riverdale, MD, 2013).

6. United States Department of Agriculture. Animal Welfare Act Regulations (US Department of Agriculture, Riverdale, MD, 2013).

Research Animal Resources Center, University of Wisconsin-Madison, Madison, WI, USA. 